\title{
Prediction of Computer Voyeurism and Stigma of the First Wave of the Coronavirus Disease-2019 Pandemic based on the Dimensions of Internet Addiction among Youth
}

\author{
Ayatollah Fathi', Solmaz Sadeghi², Saeid Sharifirahnmo ${ }^{3, *}$ iD , Hossein Rostami' ${ }^{1}$, Hamed \\ Abbasikasani ${ }^{4}$ \\ ${ }^{1}$ Assistant Professor, NAJA Institute of Law Enforcement and Social Studies, Tehran, Iran \\ ${ }^{2}$ MA in Educational Psychology, Charkh-e-Nilofari Higher Education Institute, Tabriz, Iran \\ ${ }^{3}$ PhD Candidate in Curriculum Studies, Bu-Ali Sina University, Hamadan, Iran \\ ${ }^{4}$ PhD in Information Technology in Higher Education, School of Education and Psychology, Shahid Beheshti University, \\ Tehran, Iran \\ * Corresponding Author: Saeid Sharifirahnmo, Bu-Ali Sina University, Hamadan, Iran. Email: rahnmo.70sh@gmail.com
}

\begin{tabular}{|c|c|}
\hline & Abstract \\
\hline $\begin{array}{l}\text { Received: } 30.05 .2020 \\
\text { Accepted: } 13.08 .2020\end{array}$ & \multirow[b]{2}{*}{$\begin{array}{l}\text { Background and Objective: Today, the Internet and Internet addiction are } \\
\text { among the most important issues involving the young generation. Regarding } \\
\text { the spread of coronavirus disease- } 2019 \text { (Covid-19) as a destructive factor, } \\
\text { this problem has caused mood disorders, anxiety, and aggression, which } \\
\text { need proper identification. Therefore, the present study aimed to predict the } \\
\text { computer voyeurism and stigma of the first wave of the Covid-19 pandemic } \\
\text { based on the dimensions of Internet addiction among young people. } \\
\text { Materials and Methods: This study was conducted based on a practical, } \\
\text { descriptive, and correlational design. The study population included all } \\
\text { undergraduate students in Tabriz Branch, Islamic Azad University, Tabriz, } \\
\text { Iran. Out of all students, } 252 \text { cases were selected to participate in this study } \\
\text { through an online voluntarily call due to traffic restrictions. The data were } \\
\text { collected using the Yang Internet Addiction Assessment Questionnaire, a } \\
\text { researcher-made computer voyeurism questionnaire, and a researcher-made } \\
\text { corona stigma questionnaire. The data were then analyzed using Pearson } \\
\text { statistical methods and multivariate regression. } \\
\text { Results: According to the results, all dimensions of Internet addiction } \\
\text { correlated significantly with the rate of computer voyeurism and Covid-19 } \\
\text { stigma. Out of the dimensions of Internet addiction, lack of control, and } \\
\text { negligence of professional and educational tasks can predict the extent of } \\
\text { changes in computer voyeurism and Covid-19 stigma among young people. } \\
\text { Conclusion: There is a significant relationship between the increased level } \\
\text { of Internet addiction and the power of direct prediction of computer } \\
\text { voyeurism and youth stigma. With an increase in each of the dimensions of } \\
\text { the mentioned variables, the amount of Covid-19 stigma increases, thereby } \\
\text { promoting the mood-anxiety disorders among young people. }\end{array}$} \\
\hline $\begin{array}{l}\text { How to Cite this Article: } \\
\text { Fathi A, Sadeghi S, Shari- } \\
\text { firahnmo S, Rostami H, Abbasi- } \\
\text { kasani H. Prediction of Computer } \\
\text { Voyeurism and Stigma of the } \\
\text { First Wave of the Coronavirus } \\
\text { Disease-2019 Pandemic based } \\
\text { on the Dimensions of Internet } \\
\text { Addiction among Youth. } \\
\text { Avicenna J Clin Med. 2020; } \\
\text { 27(2): 124-132. DOI: 10.29252/ } \\
\text { ajcm.27.2.124 }\end{array}$ & \\
\hline & Keywords: COVID-19, Health, Internet Addiction, Stigma, Voyeurism \\
\hline
\end{tabular}


dof: $10.29252 / \mathrm{ajcm} \cdot 27.2 .124$

\section{ييشبينى ويريسم رايانهاى و استيكماى موج اول إيدمى كرونا بر اساس ابعاد اعتياد اينترنتى در بين جوانان}

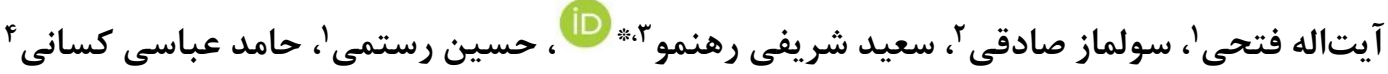

' استاديار، يزوهشكاه علوم انتظامى و مطالعات اجتماعى ناجا، تهران، ايران

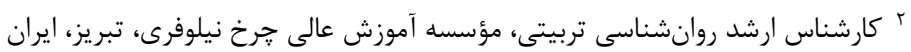

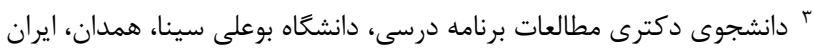

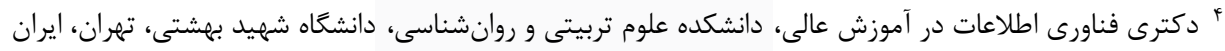
* نويسنده مسئول: سعيد شريفى رهنمو، دانشخاه بوعلى سينا، همدان، ايران. ايميل: rahnmo.70sh@gmail.com

\section{جكيده}

سابقه و هدف: امروزه يكى از مسائل مهمى كه نسل جوان با آن دركير هستند، اينترنت و اعتياد به آن است.

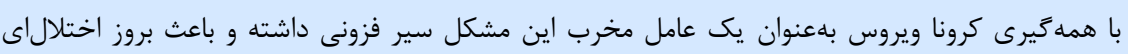

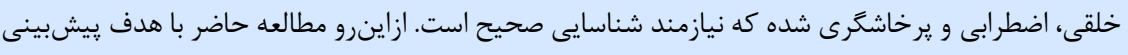

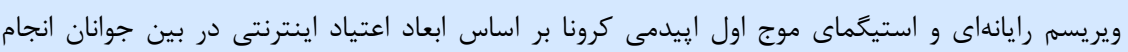

$$
\text { يذيرفت. }
$$

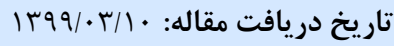

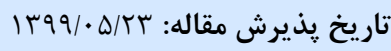
تمامى حقوق نشر براى دانشكاه علوم يزشكى همدان محفوظ است.

مواد و روش ها: اين مطالعه از نظر هدف، كاربردى و از نظر ماهيت و روش، توصيفى از نوع همبستخى است.

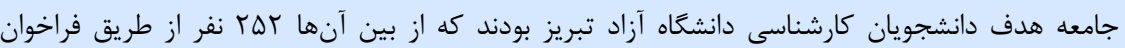

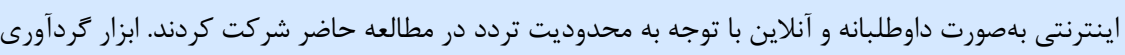

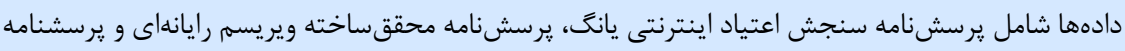

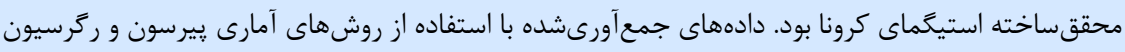
קندمتغيره تجزيهوتحليل شدند.

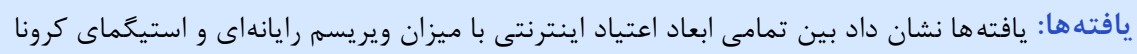

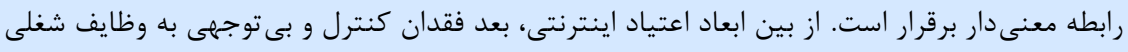

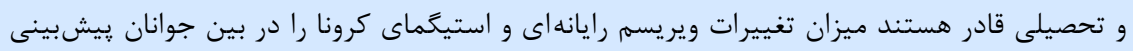
كنند. نتيجه كَيرى: بين زيادبودن ابعاد اعتياد اينترنتى و قدرت يیشبينى مستقيم ويريسم رايانهاى و استيخماى

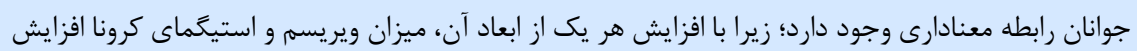

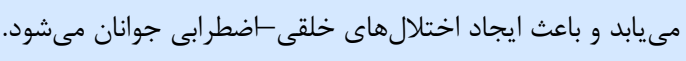
وازَّان كليدى: استيگما، اعتياد اينترنتى، بهداشت، كرونا ويروس، ويريسم
قسمت آن تبديلشدن جهان به يك كلبه واحد است. در جنين

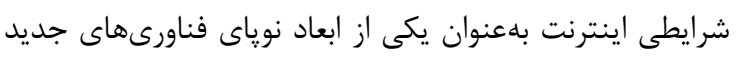

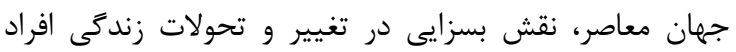

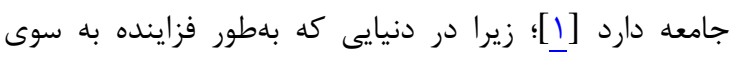

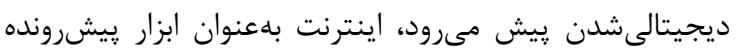

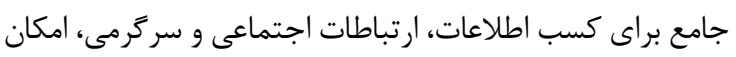

بسيارى از دانشمندان و صاحبنظران علوم اجتماعى بر اين

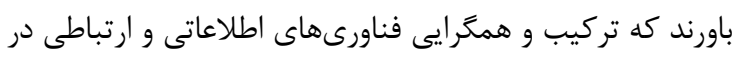

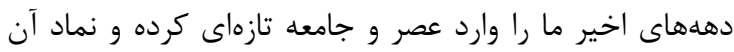

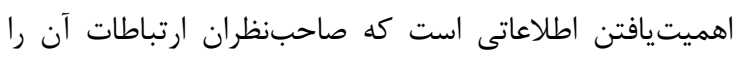

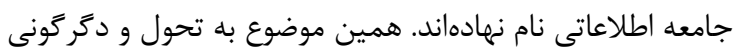

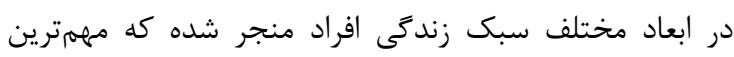


كرفته شود كه متأسفانه تحقيقات بسيار كمى درباره آن صورت آرات

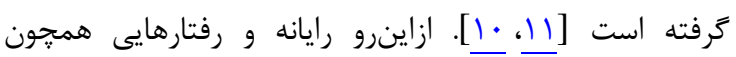

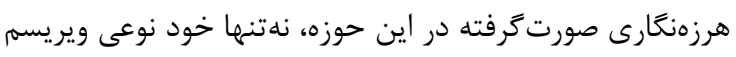

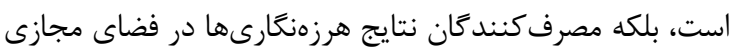

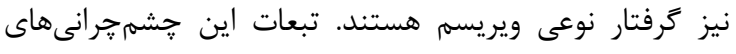

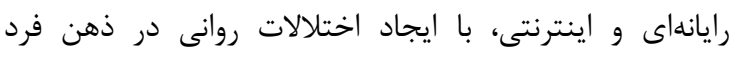

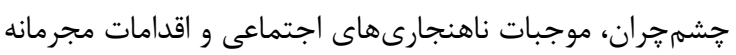

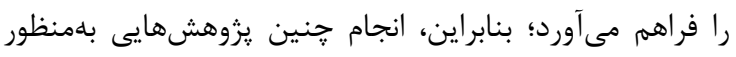

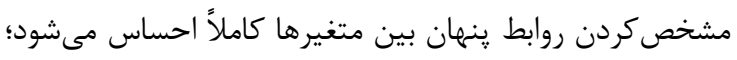

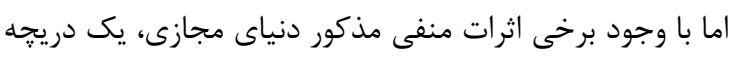

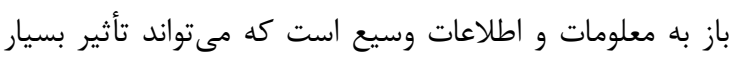

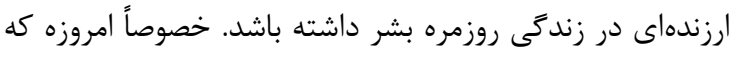

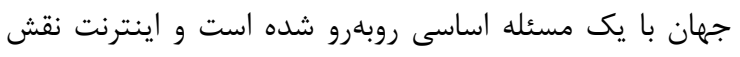

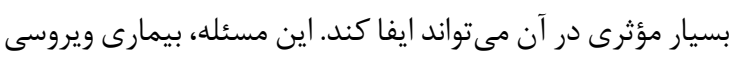

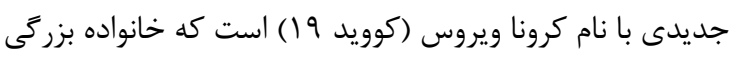

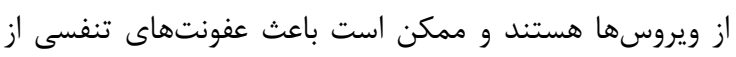

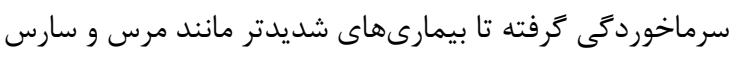
شوند [1 II].

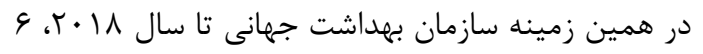

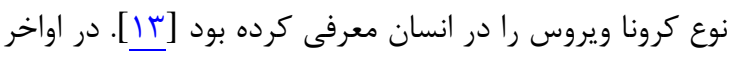

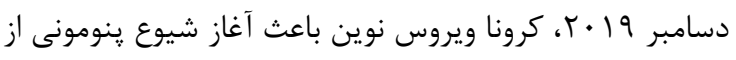

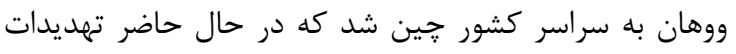

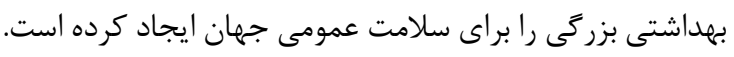

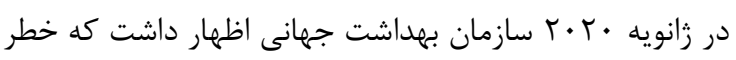

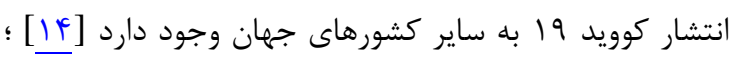

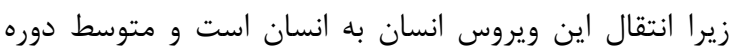

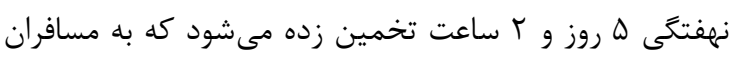

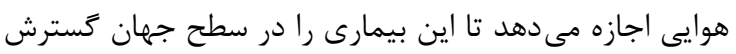

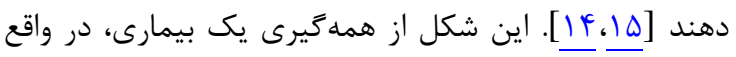

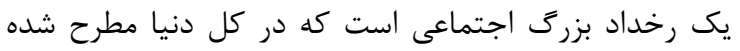

حال لازم است آثار روانى اين بيمارى نيز مورد توجه قرار

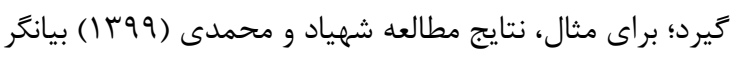

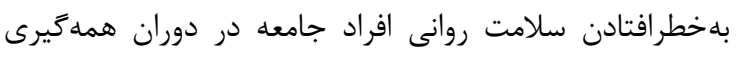

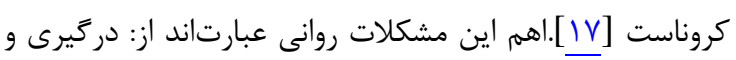

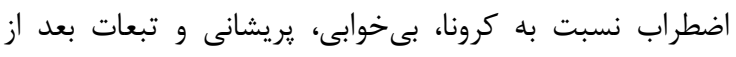

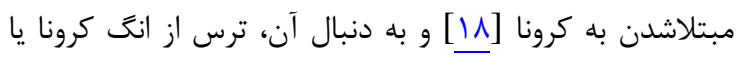
ترس از استيخما. اصطلاح استيگما وازماى يونانى است كه نخستين بار يونانيان

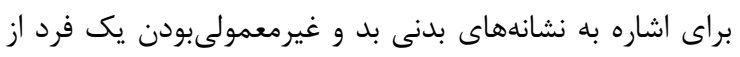

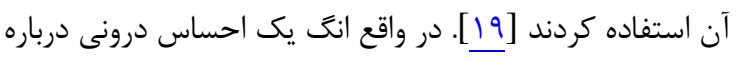

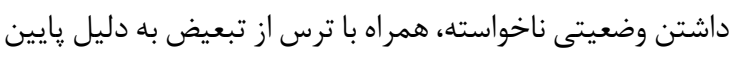

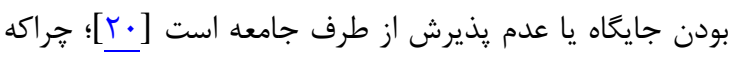

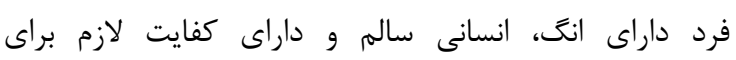

ارتباط همزمان و نامحدود افراد را فارغ از تعلق مكانى فراهم

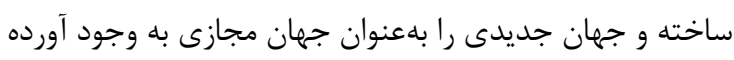

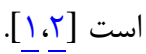
در اوايل دهه • •191، دانشمندان رايانه و رسانهها اصطلاح

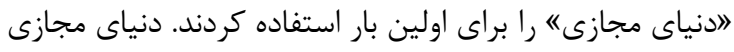

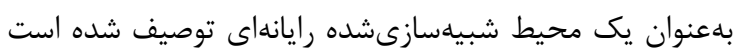

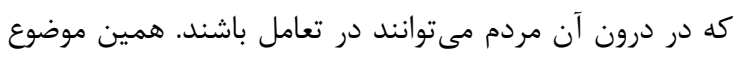

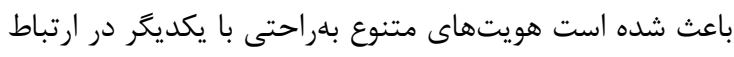

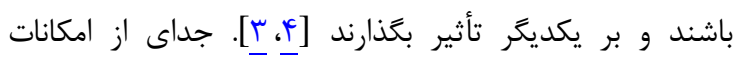

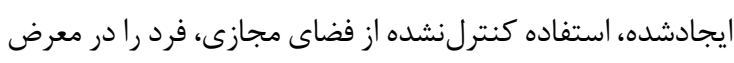

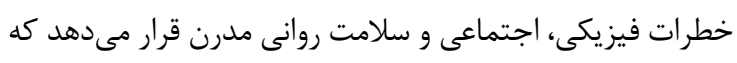

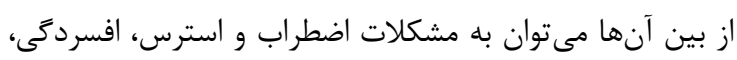

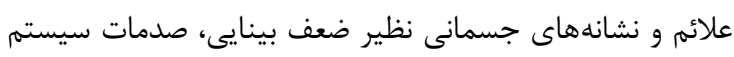

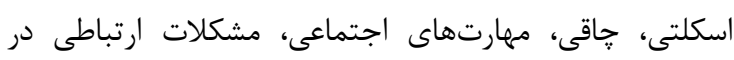

خانواده و از همه مههمتر اعتياد الكترونيكى اشاره كرد [هـإ].

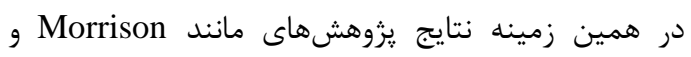

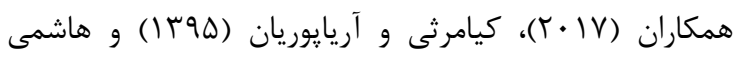

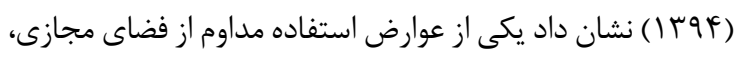

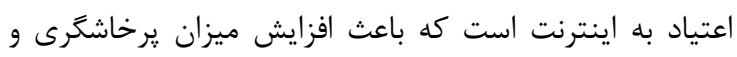

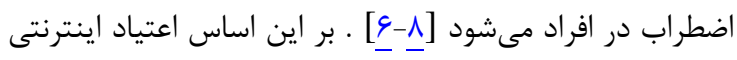

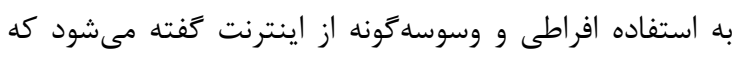

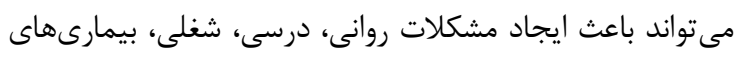

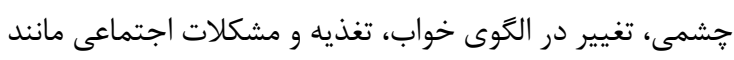

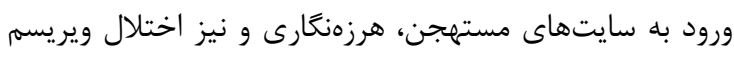

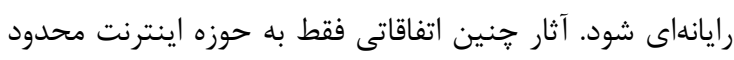

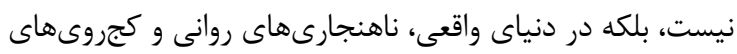

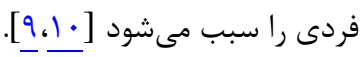

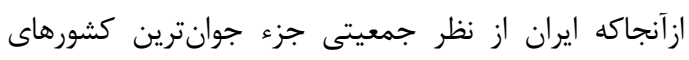

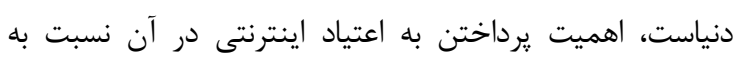

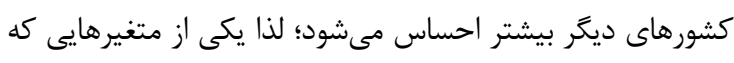

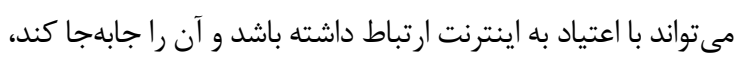

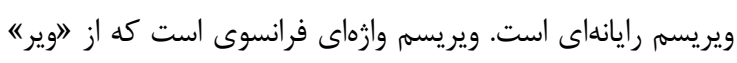

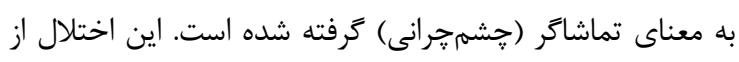

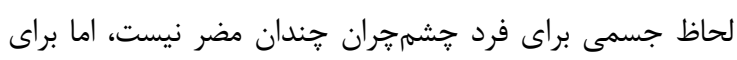

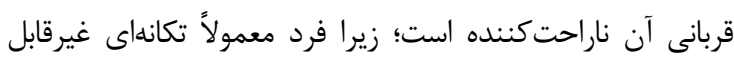

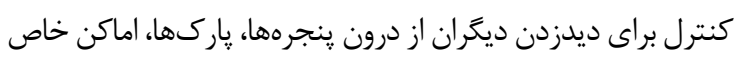

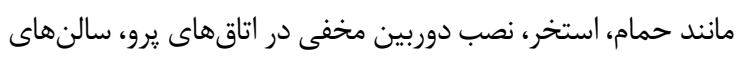

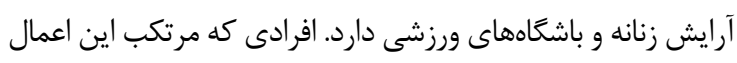

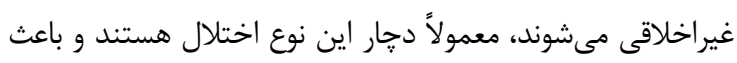

ايجاد نامنى روانى در ديكران مىشوند [111]

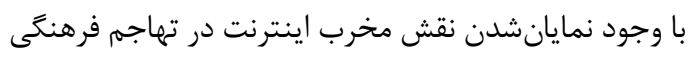

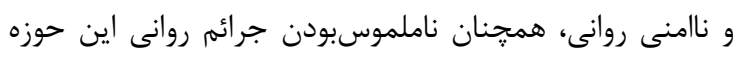

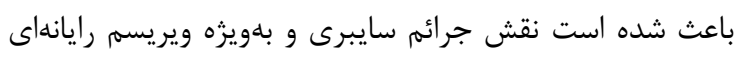

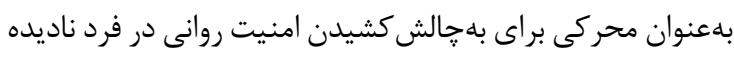


يزوهش از مطالعات كتابخاناي و براى آزمون فرضيهها از روش همبستكى استفاده شد. جامعه آمارى اين مطالعه تمام دانشجويان

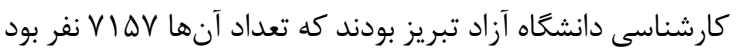

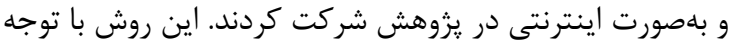

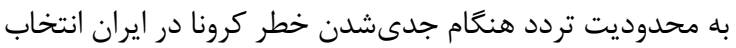

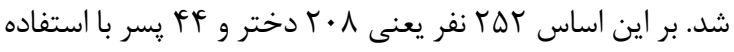

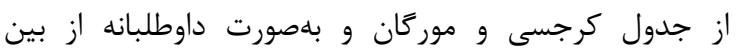

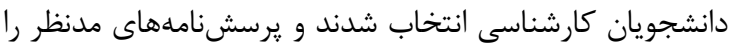

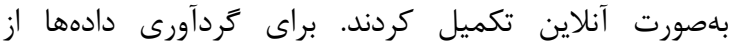
يرسشنامهاى زير استفاده شد.

\section{برسشنامه سنجش اعتياد/ ينترنتس يانتَ}

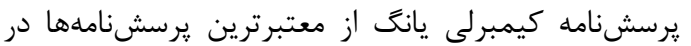

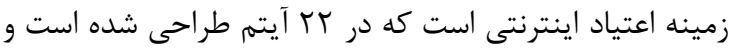

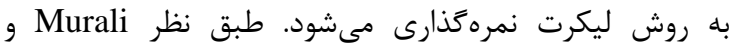

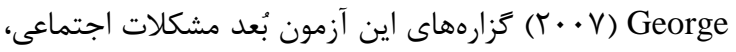

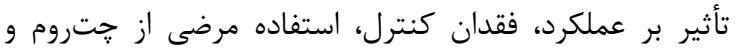

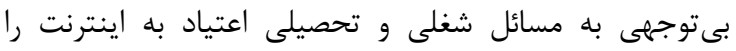

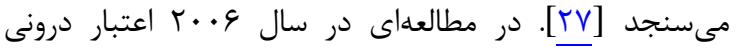

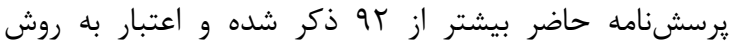

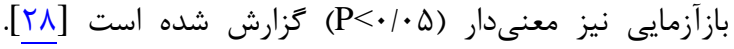
Midyanto بررسى ويزگ هاى روانسنجى يرسشنامه اعتياد اينترنتى يانكَ،

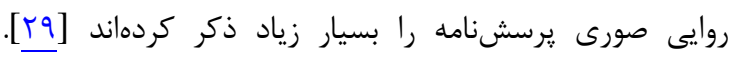

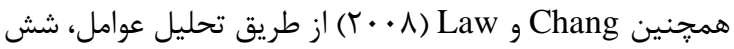

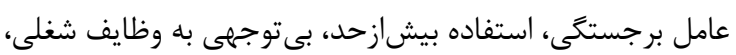

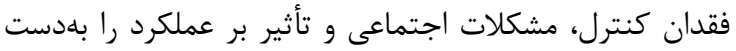

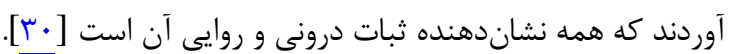

\section{برسشنامه سنجش ميزان ويريسم رايانهاى} يرسشنامه حاضر محققساخته است و ميزان ويران ويريسم

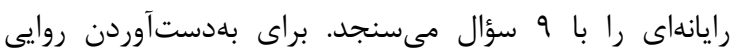

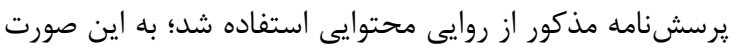

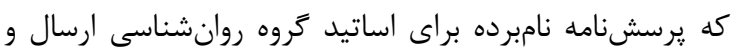

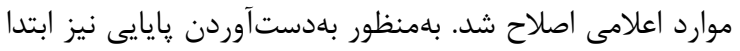

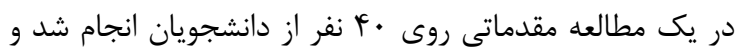

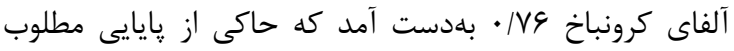
يرسشنامه است. بعد از اجراى كامل نيز ضريب آلهاي آلفاى كرونباخ

\section{يرسشنامه انََ اجتماعى (استيكَماى كرونا)}

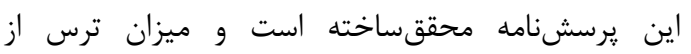

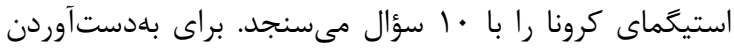

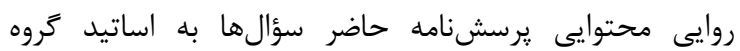

يذيرفتهشدن در اجتماع در نظر كرفته نمىشود [إr]؛ لذا ترس

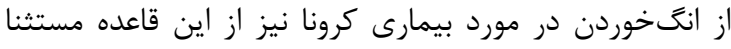

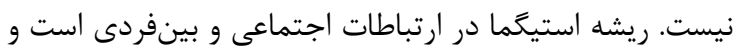

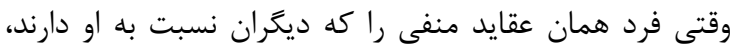
درباره وضعيت خودش در ذهن بيروراند، دجار استيخماى درونى دئى

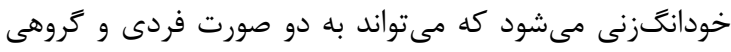
ايجاد شود [r آس]. در همين راستا با توجه به انبوه اطلاعات نادرست در اينترنت

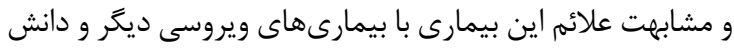

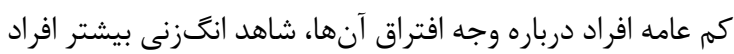

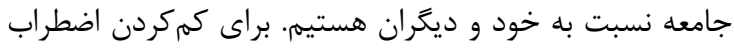

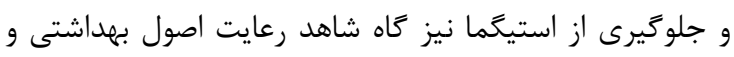

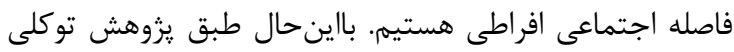

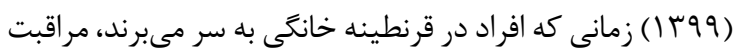

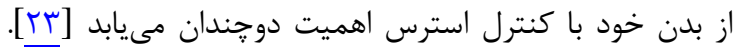

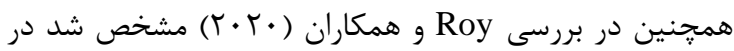

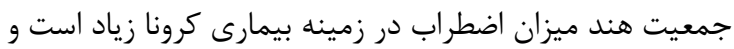

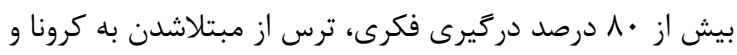

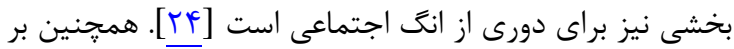

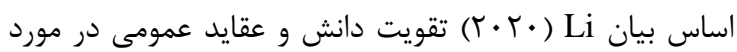

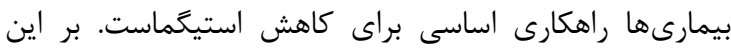

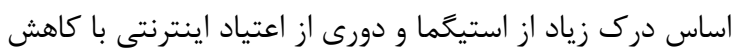

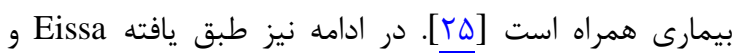

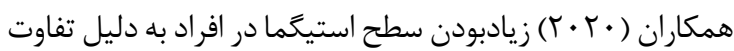

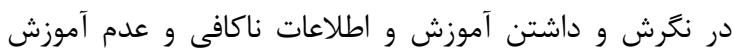

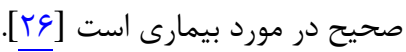

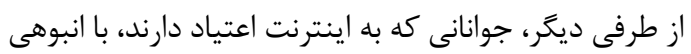

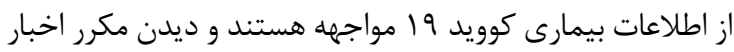

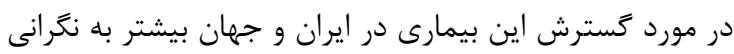

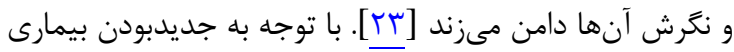

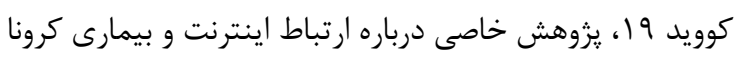

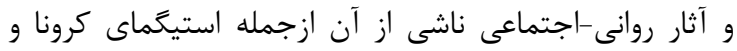

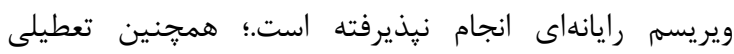

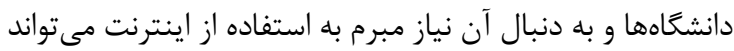

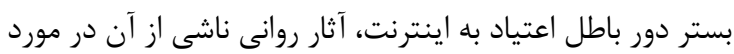

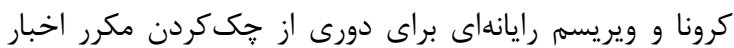

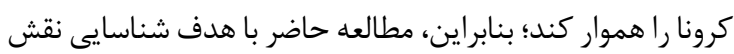

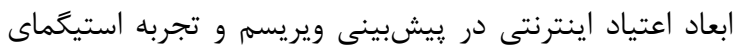

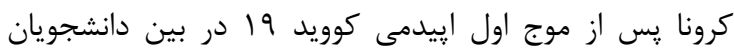

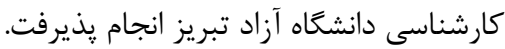

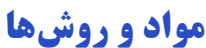

مطالعه حاضر از نظر هدف، كاربردى و از نظر ماهيت و روش،

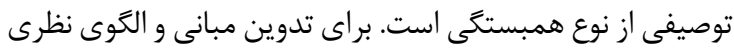




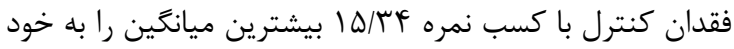

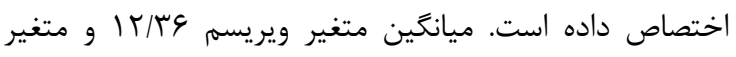

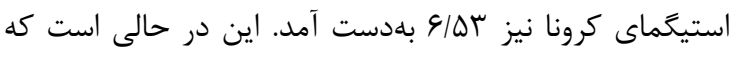

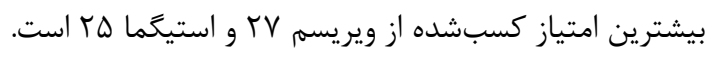

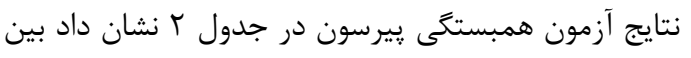

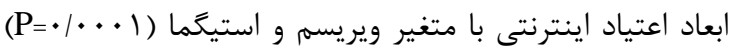

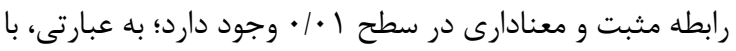

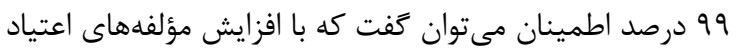

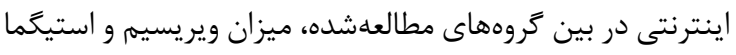

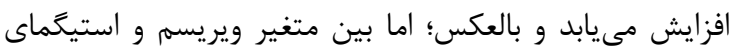

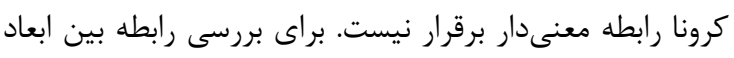

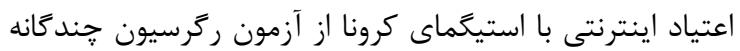

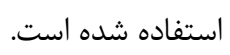

نتايج آزمون تحليل ركرسيون نشان داد ابعاد اينترنتى

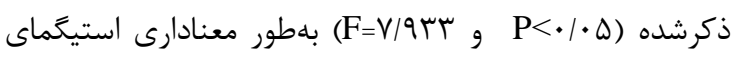
كروناى جوانان را بيشبينى مى كند (جدول س)
روانشناسى و جامعهشناسى عرضه و موارد اعلامى اصلاح شد.

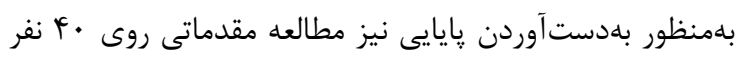

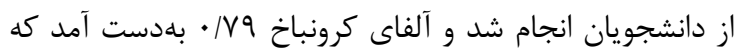

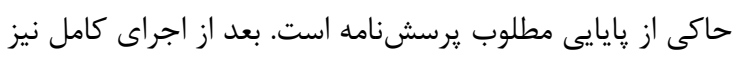

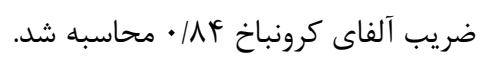

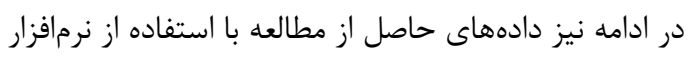

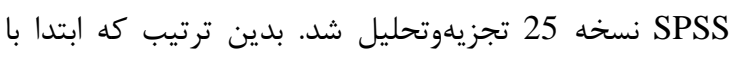

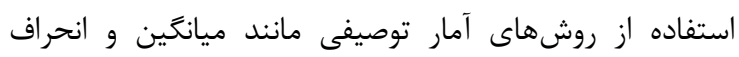

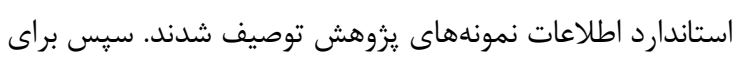

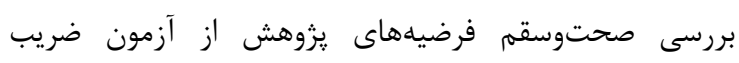

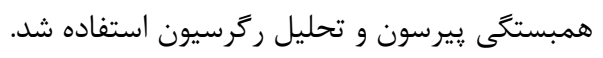

يافته ها

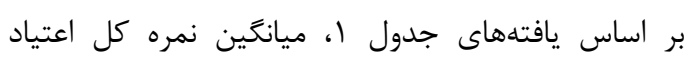

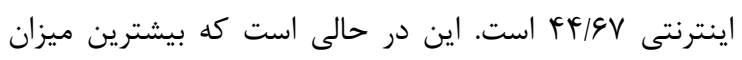

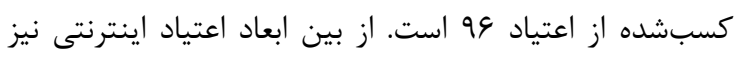

جدول ا: ابعاد توصيفى متغيرها

\begin{tabular}{|c|c|c|c|c|}
\hline 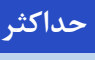 & 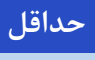 & انحراف معيار ذميانَين & & 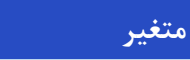 \\
\hline TQ & 9 & $1 \cdot / V \Delta \pm F / r q$ & مشكلات اجتماعى & \\
\hline iv & f & $V / I r \pm T / 19$ & تأثير بر عملكرد & \\
\hline rA & $\checkmark$ & $|Q / Y \Psi \mp \pm \Delta / \Delta|$ & فقدان كنترل & اعتياد اينترنتى \\
\hline 10 & r & $\Delta / \| \pm T / T r$ & استفاده مرضى از جتروم & \\
\hline 10 & r & $9 / r r \pm T / \Lambda$. & بى توجهى به وظايف شغلى و تحصيلى & \\
\hline 94 & r & $|F \Psi / \& \vee \pm| / 9 \mid$ & نمره كل اعتياد اينترنتى & \\
\hline TV & 9 & $\mid r / T \varphi \pm F / \Delta T$ & 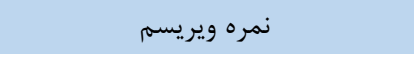 & 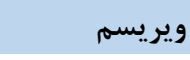 \\
\hline ro & - & $\varepsilon / \Delta r \pm \Delta / \cdot V$ & نمره استيخماى كرونا & استيخما \\
\hline
\end{tabular}

\begin{tabular}{|c|c|c|c|c|c|c|c|c|c|}
\hline$\wedge$ & $\checkmark$ & 9 & $\Delta$ & f & r & $r$ & 1 & متغير & \\
\hline & & & & & & & 1 & ويريسم & 1 \\
\hline & & & & & & 1 & $.1 .19 q$ & استيخماى كرونا & $r$ \\
\hline & & & & & 1 & $\cdot / K \Lambda 8^{* *}$ & $\cdot /\left.\pi 9\right|^{* *}$ & مشكلات اجتماعى & $r$ \\
\hline & & & & 1 & $\cdot / \Lambda \cdot 9^{* * * *}$ & . MIV & $\cdot / 191^{* *}$ & تأثير بر عملكرد & r \\
\hline & & & 1 & $\cdot|\Lambda| V^{*}$ & $\cdot \mid \Lambda \cdot V^{*}=$ & $\cdot \pi \Delta \Delta^{* *}$ & $\cdot \pi r \omega^{* *}$ & فقدان كنترل & $\Delta$ \\
\hline & & 1 & . $/ \Delta T T^{\prime *}$ & $\cdot \mid \Delta V K^{\approx * * \omega}$ & $.1919^{* * * *}$ & $\cdot / r \cdot . *$ & $\cdot / r \Lambda \cdot=$ & استفاده مرضى از جتروم & 4 \\
\hline & 1 &.$|99|^{*}$ & $\cdot N \Lambda Y^{*}=$ & $\cdot N \cdot 9^{*}=$ & $\cdot / V \Lambda r^{* * *}$ & $\cdot R r \Lambda^{\text {棏 }}$ & $\cdot R \wedge r^{*}$ & بىتوجهى به تحصيل & v \\
\hline 1 & $\cdot / \Lambda \Lambda \Delta^{\circ}$ & $\cdot N 19^{* * *}$ &.$/ 941^{\text {垶 }}$ & $\cdot / 19 \Lambda^{*}=$ & 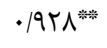 & 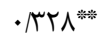 & $\cdot|r \Lambda|^{*}$ & اعتياد اينترنتى & $\wedge$ \\
\hline
\end{tabular}

جدول با: تحليل واريانس اثر ميزان اعتياد اينترنتى بر استيكماى كرونا

\begin{tabular}{|c|c|c|c|c|c|c|c|}
\hline $\mathbf{R}^{2}$ & $\mathbf{R}$ & sig & Fاره Fار F & ميانَين مجذورات & درجه آزادى & مجموع مجذورات & مدل \\
\hline \multirow[t]{3}{*}{.$/ 1 r q$} & $\cdot r V r$ & $.1 . .1$ & V/qur & $I V q / V \cdot r$ & $\Delta$ & $\Lambda ৭ \wedge / \Delta$. & ركرسيون \\
\hline & & & & $r Y / 9 \Delta \mid$ & TYS & $\Delta D V T / T T$ & باقى مانده \\
\hline & & & & & TAI & $G F V \cdot / V F$ & كل \\
\hline
\end{tabular}


جدول f: ضرايب رَرسيونى خطى يِشبين استيخماى كرونا

\begin{tabular}{|c|c|c|c|c|c|}
\hline sig & آماره t & ضريب ركر سيون استاندارد & خطاى معيار & ضريب رَر سيون & متغير ها \\
\hline$\cdot 1148$ & $1 / F \Delta q$ & & • /949 & $1 /$ KदG & مقدار ثابت \\
\hline$\cdot / \cdot \wedge \Delta$ & $-I / V \Gamma \Lambda$ & $-\cdot / \mu \cdot 1$ & $\cdot \pi \cdot r$ & $-\cdot / r \Delta \cdot$ & مشكلات اجتماعى اجى \\
\hline$\cdot|f| V$ & $-\cdot|\lambda| t$ & $-\cdot / 1 r \cdot$ & $\cdot / T \Delta V$ & $-\cdot / 4 \cdot 9$ & تأثير بر عملكرد \\
\hline$\cdot 1 \cdot \cdot 1$ & $91 \cdot \cdot \Delta$ & $\cdot / r \Delta \Delta$ & $\cdot / \cdot \Delta F$ & - MTV & فقدان كنترل \\
\hline$\cdot / T F A$ & $-1 / 1 \Delta V$ & $-\cdot / 1 \cdot \Delta$ & .1191 & $-\cdot / r T q$ & استفاده مرضى از جتروم \\
\hline$\cdot / \cdot 1 \cdot$ & $-T / 4 \cdot r$ & $-\cdot / \Upsilon \wedge \vee$ & $\cdot / 499$ & $\cdot / \mathrm{V} \cdot$ & بى توجهى به وظايف شغلى و تحصيلى \\
\hline$\cdot 1 \cdot r$ & $r /|Q|$ & $1 / 1 \mathrm{Fr}$ & $.111 \mathrm{~F}$ & $\cdot / \pi \Delta q$ & نمره كل اعتياد اينترنتى \\
\hline
\end{tabular}

جدول ه: ضرايب ركرسيون جندگًانه يِيشبينى ويريسم رايانهاى

\begin{tabular}{|c|c|c|c|c|c|}
\hline sig & $\mathbf{t}$ & B & $\mathbf{R}^{2}$ & $\mathbf{R}$ & متغير ها \\
\hline$\cdot 1 \cdot \cdots 1$ & $\Lambda / V \wedge$ & שוא. & \multirow{5}{*}{$\cdot \mid \wedge \varepsilon$} & \multirow{5}{*}{$\cdot 191$} & مشكلات اجتماعى \\
\hline .1 .91 & -119 & $-\cdot 1 \cdot 9$ & & & تأثير بر عملكرد \\
\hline$\cdot 1 \cdot \cdots 1$ & $11 / 14$ & $\cdot / F \Delta$ & & & 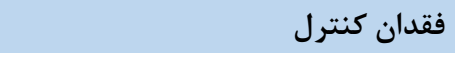 \\
\hline$\cdot / r V$ & $-\cdot / V \wedge$ & $-\cdot / \cdot r$ & & & استفاده مرضى از جتروم \\
\hline$\cdot 1 \cdots 1$ & F/IT &.$/ 1 \mathrm{~F}$ & & & بى توجهى به وظايف شغلى و تحصيلى \\
\hline
\end{tabular}

نوآورى يروهش حاضر با توجه به همين نكته و تمركز بر اضطرابهاى كرونايى با توجه به ويريسم رايانهاى و استيخما انجام

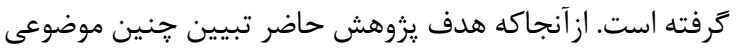

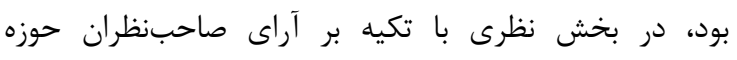

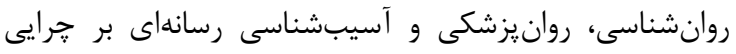

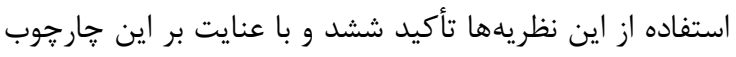

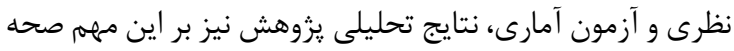
كذاشت و فرضيه هاى يزوهش را تأييد كرد.

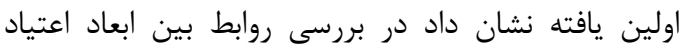

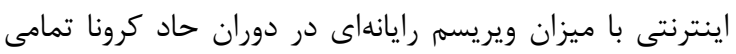

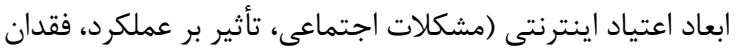

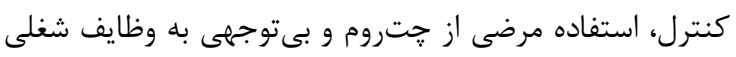
و تحصيلى) رابطه مثبت و معنى دارى با ويريسم دارند؛ بنابر اين،

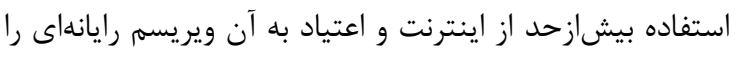

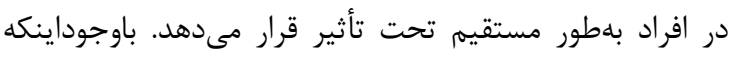

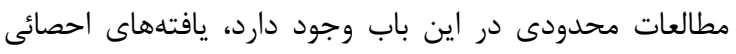

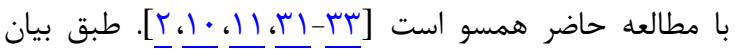
Masih و اندوه، احساس افتادگى و ازدستدادن علاقه به فعاليتهاى

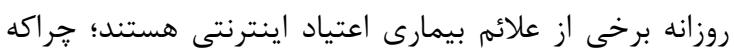

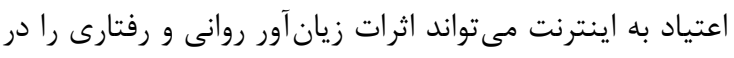

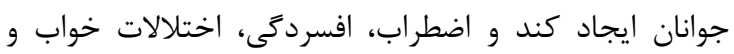

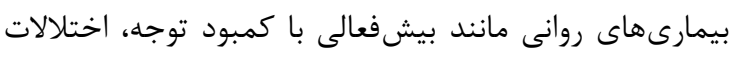

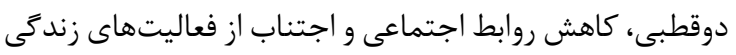

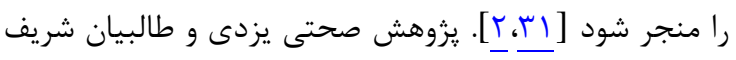

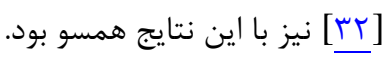

با توجه به نتايج جدول fأ مىتوان كفت كه در ميان شاخصهاى كنجاندهشده در مدل، بيشترين توانايى مستقيه در

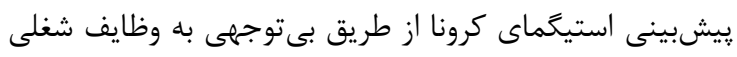

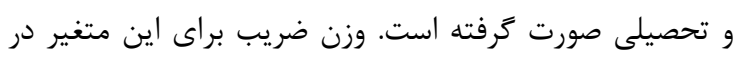

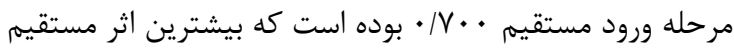
را روى متغير وابسته داشته است. دومين متغير فقدان كنترل

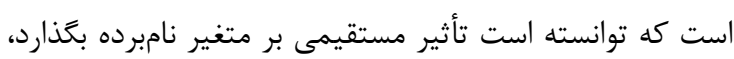

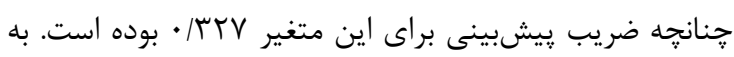

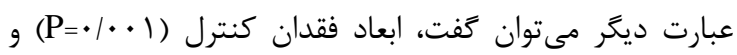

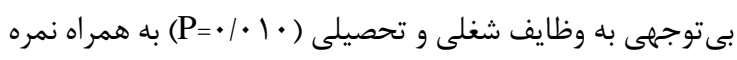

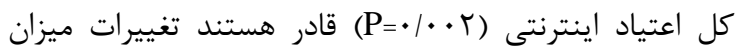
استيخماى كروناى جوانان را ڤيشبيشينى كنيند.

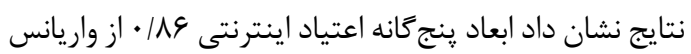

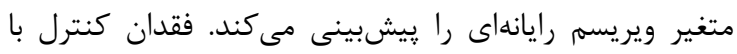

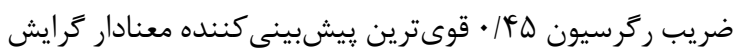

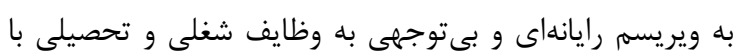

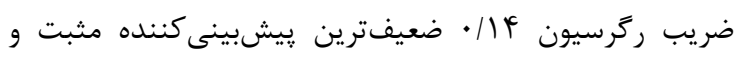

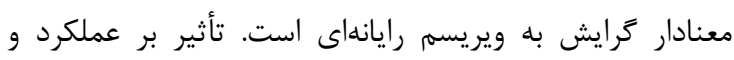

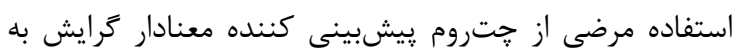

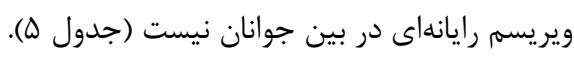

بجث

مطالعه حاضر با هدف شناسايى ميزان يِيشبينى ويريسم

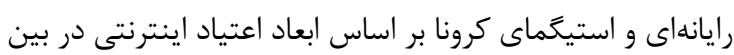

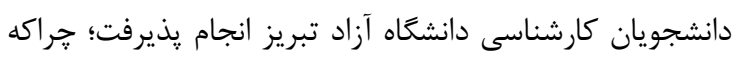
درباره جنين موضوعى هيج يزوهش خاصى انجى انجام نشده است. 
وارده در هر محيط از كشورى به كشور ديخر و حتى از شهرى به إنه

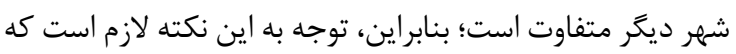

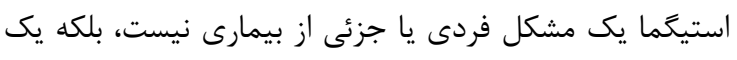

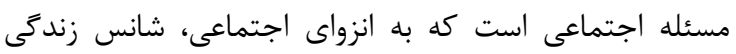

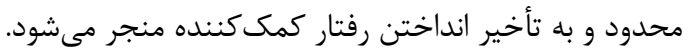

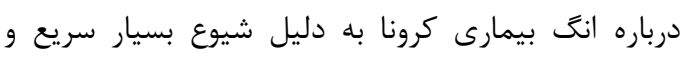

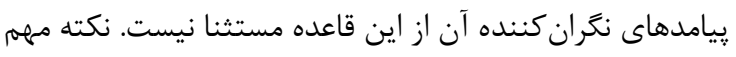

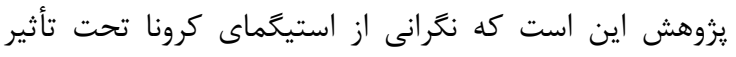

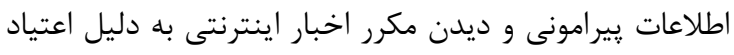

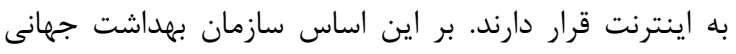

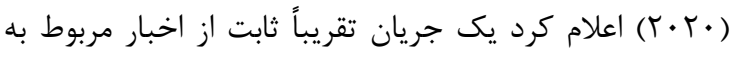

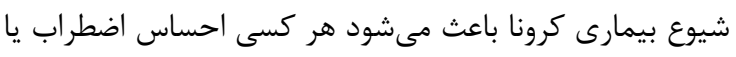

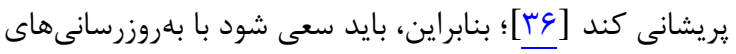

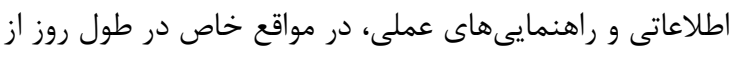

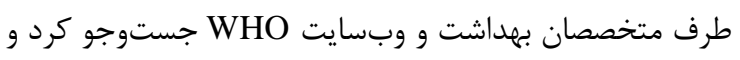

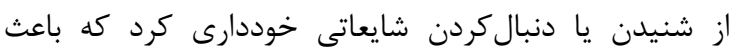

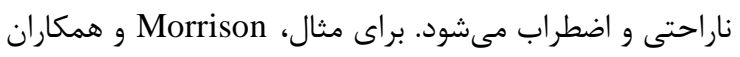

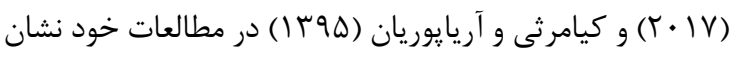
دادند هر اندازه ميزان استفاده و درنتيجه اعتياد اينترنتى زيان إنياد

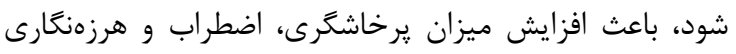

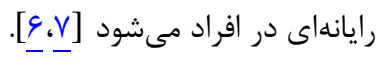

\section{نتيجه تيرى}

با توجه به نتايج بهدستآمده مىتوان كفت كه استفاده

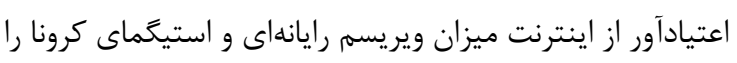

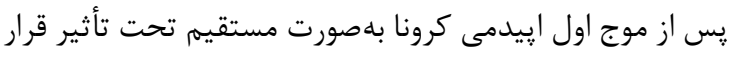

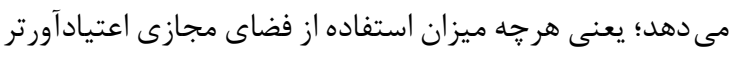

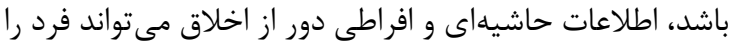

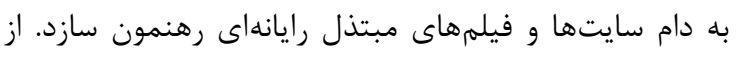

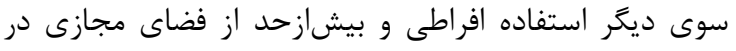

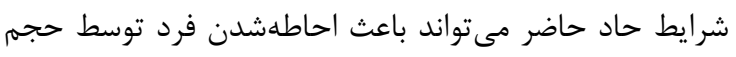

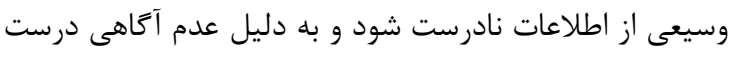

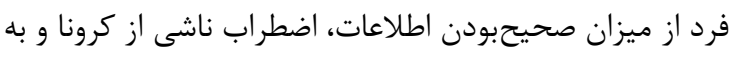

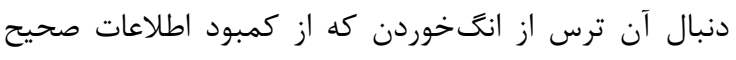

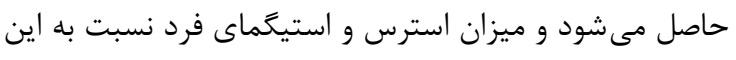

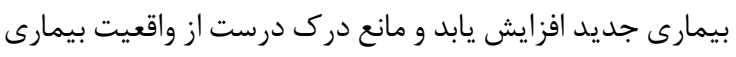

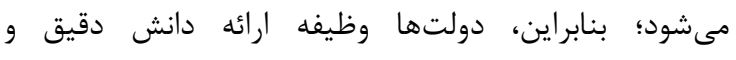

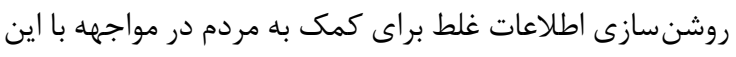

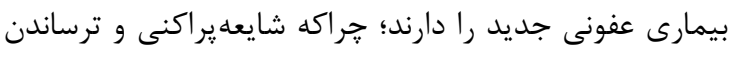

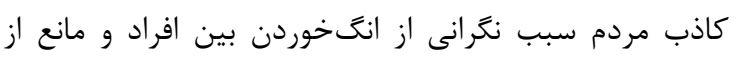

$$
\text { بيخيرى صحيح آنها مىشود. }
$$

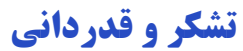

اين مقاله از بخشى از طرح تحقيقاتى مصوب دانشعاه تبريز
در همين راستا مطالعات محدود انجاميافته در زمينه اختلال

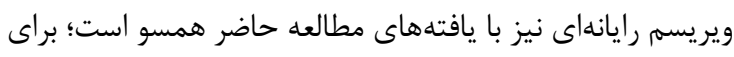

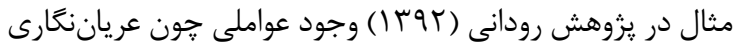

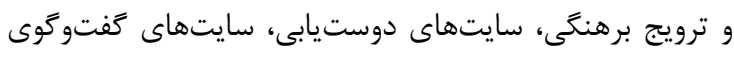

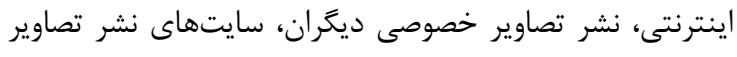

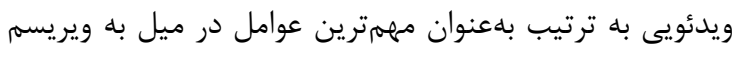

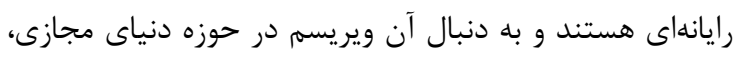

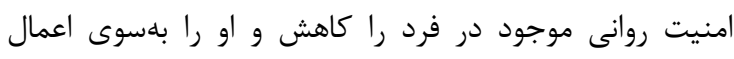

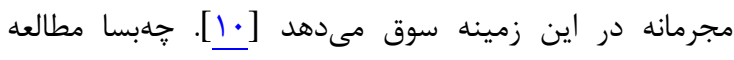
و Barany

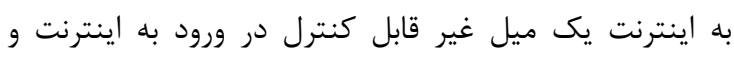

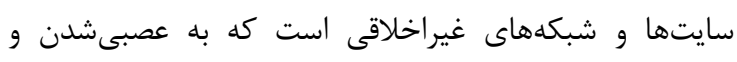

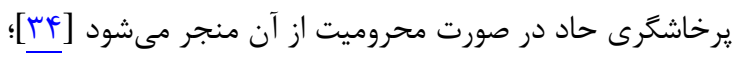

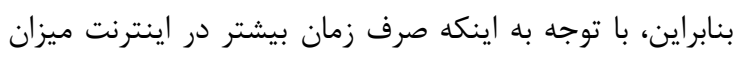

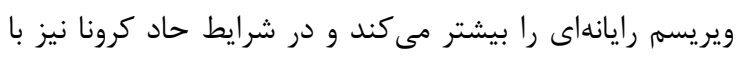

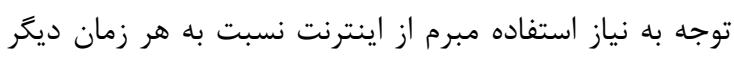

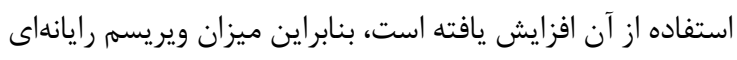
نيز افزايش بيدا مي كند.

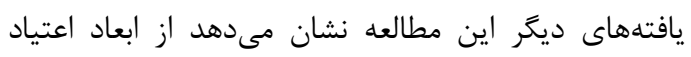

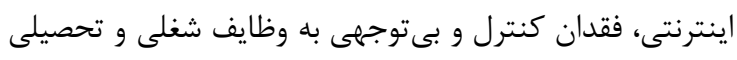

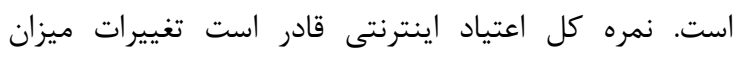

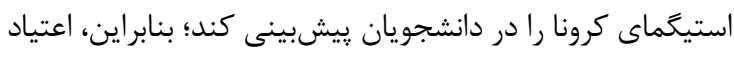

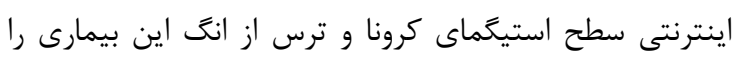

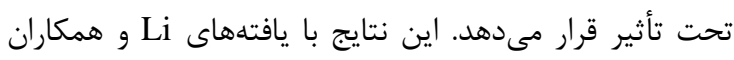

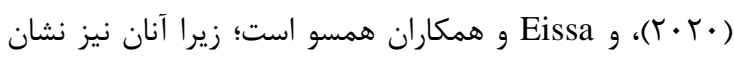

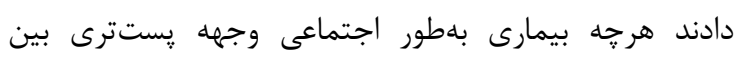

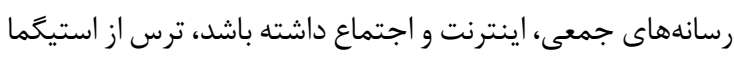

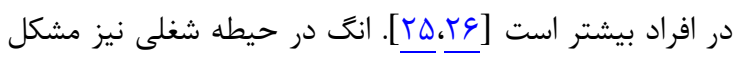

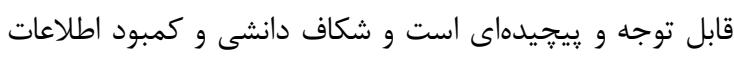

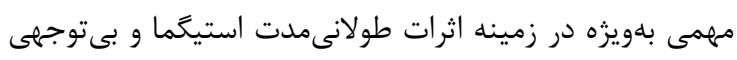

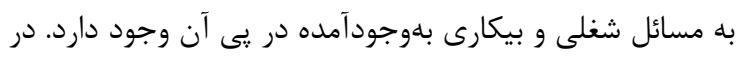

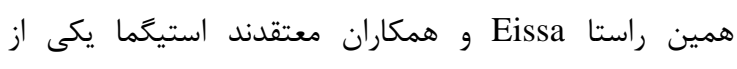

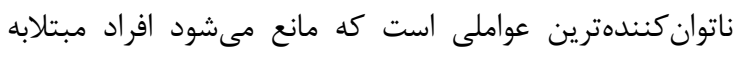

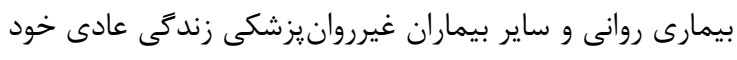

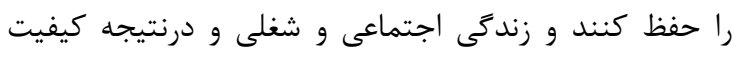

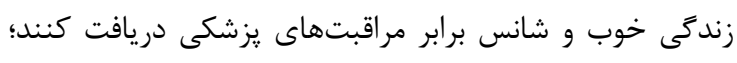

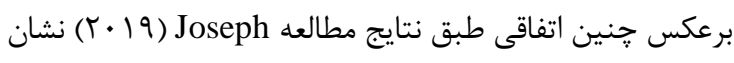

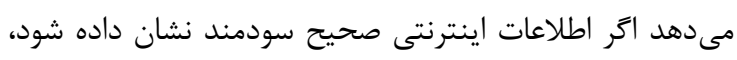

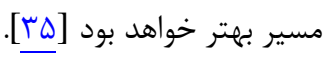

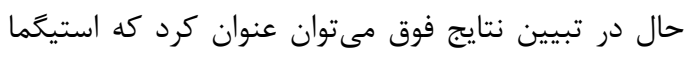

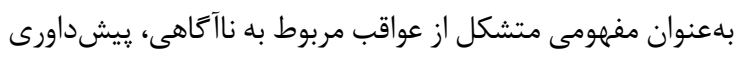

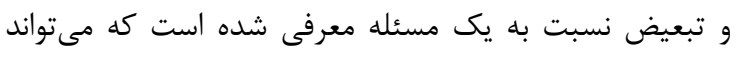

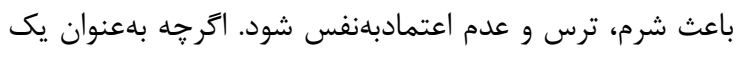
يديده جهانى شناخته شده است، تجربه لمس آن و وتبعيض هاد 


$$
\begin{aligned}
& \text { سهم نويسنانكان }
\end{aligned}
$$

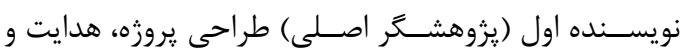

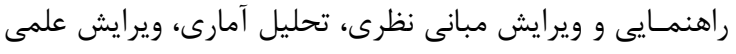

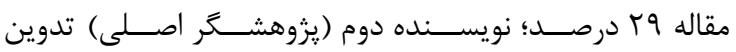

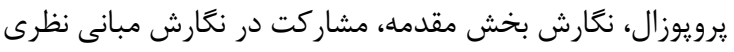

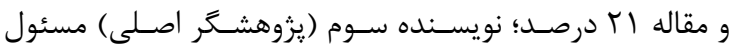

$$
\begin{aligned}
& \text { مكاتبات، مشاركت در طراحى يروزه، تدوين بخش نتايج و بحث، }
\end{aligned}
$$

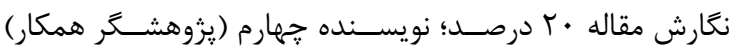

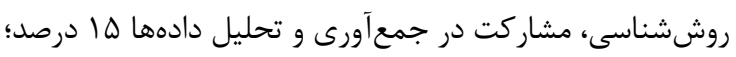

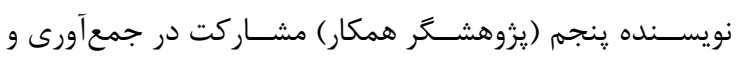

$$
\begin{aligned}
& \text { تحليل دادهها ها درصد. }
\end{aligned}
$$$$
\text { حمايت مالى }
$$$$
\text { يزوهش حاضر از سوى هينج سازمانى حمايت مالى نشده }
$$

\section{REFERENCES}

1. Naeinian MR, Adabdoost F, Khatibi S, Ghomian F. Use of internet and its relationship with mental health and life quality of high school students. Sci J Clin Psychol Person. 2017;14(2):103-13. DOI: 10.22070/14.2.103 [Persian]

2. Turi A, Miri M, Beheshti D, Yari E, Khodabakhshi H, Anani Sarab G. Prevalence of internet addiction and its relationship with anxiety, stress, and depression in intermediate students in Birjand city in 2014. J Birjand Univ Med Sci. 2015; 22(1):67-75. [Persian]

3. Gorini A, Riva G. Virtual reality in anxiety disorders: the past and the future. Expert Rev Neurother. 2008;8(2):215-33. PMID: 18271709 DOI: 10.1586/14737175.8.2.215

4. Khojasteh S, Mirhosseini SA. The relationship between of social networks and mental health and national religious identity of secondary school students of district 1 of Kerman. Quart J Educ Sociol. 2018;11:99-112. [Persian]

5. Jafariharandi R, Bahrami S. The effect of internet addiction, mental and spiritual health of students at Qom University. Sci J Manag Syst. 2019;1(14):55-77. [Persian]

6. Morrison AP, French P, Wells A. Metacognitive beliefs across the continuum of psychosis: comparisons between patients with psychotic disorders, patients at ultra-high risk and non-patients. Behav Res Ther. 2007;45(9):2241-6. PMID: 17316556 DOI: 10.1016/j.brat.2007.01.002

7. Kiamarsi A, Aryapooran S. Prevalence of internet addiction and it relationship with academic procrastination and aggression in students. J Sch Psychol. 2015;4(3):67-85. [Persian]

8. Hashemi M, Darvize Z, Yazdi SM. Comparison of psychological hardiness and cognitive emotion regulation in students with social anxiety disorder and normal students. Psychol Stud. 2014;15(1):41-56. [Persian]

9. Ebrahimi S, Khammarnia M, Porvazn N, Karamipur M, Jamshidzahi H, Setoodezadeh F, et al. The prevalence of internet addiction and its relationship with quality of sleep and quality of life among students of Zahedan university of medical Sciences. J Sch Public Health Institute Public Health Res. 2018;16(2):126-37. [Persian]

10. Rudani A, Raisi Vanani R, Nazer Hazrat J. Analysis of the relationship between computer voyeurism and psychological security the person committing the virus. Soc Secur Stud Quart. 2013;34:143-72. [Persian]

11. Hejazi A, Dalki S, Badieian MN, Zarenejad M. A case of sexual sadism with some kinds of paraphilias. Sci J Forensic Med. 2010;15(4):266-9. [Persian]

12. Alipour A, Ghadami A, Alipour Z, Abdullahzadeh H. Preliminary validation of corona anxiety scale (CDAS) in the

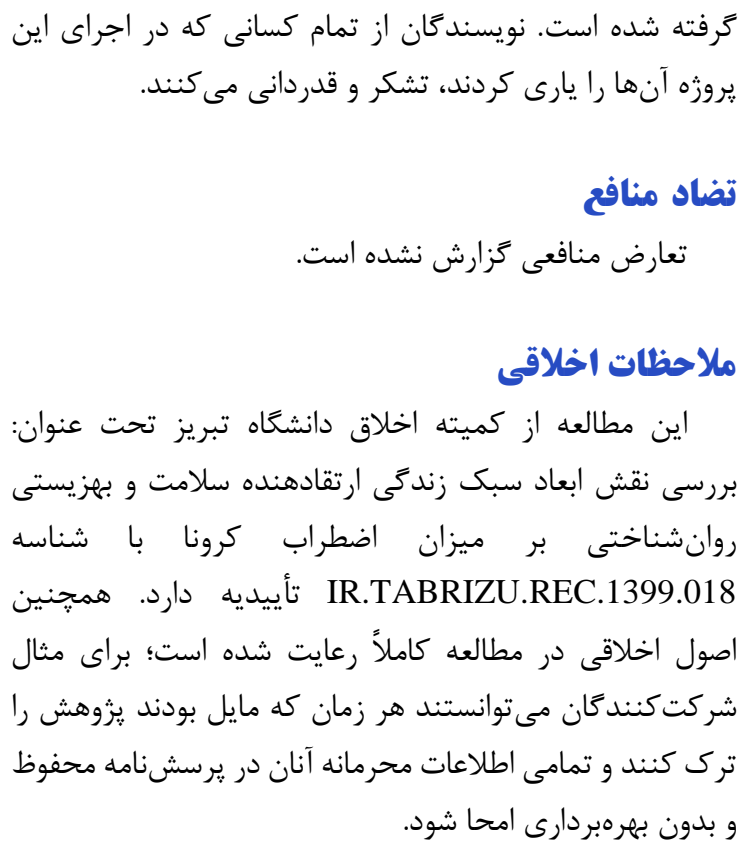

Iranian sample. Quart J Health Psychol. 2020;8(4):163-75. [Persian]

13. Corman VM, Muth D, Niemeyer D, Drosten C. Hosts and sources of endemic human coronaviruses. Adv Virus Res. 2018;100:163-88. PMID: 29551135 DOI: 10.1016/bs.aivir. 2018.01.001

14. Farnoosh G, Alishiri G, Hosseini Zijoud SR, Dorostkar R, Jalali Farahani A. Understanding the severe acute respiratory syndrome Coronavirus 2 (SARS-CoV-2) and coronavirus disease (COVID-19) based on available evidence - a narrative review. J Mil Med. 2020;22(1):1-11. [Persian]

15. Kooraki S, Hosseiny M, Myers L, Gholamrezanezhad A. Coronavirus (COVID-19) outbreak: what the department of radiology should know. J Am Coll Radiol. 2020;17(4):44751. PMID: 32092296 DOI: $10.1016 /$ j.jacr.2020.02.008

16. Alizadeh FS, Saffarinia M. The prediction of mental health based on the anxiety and the social cohesion that caused by Coronavirus. Soc Psychol Res. 2020;36:129-41. [Persian]

17. Shahyad S, Mohammadi MT. Psychological impacts of Covid-19 outbreak on mental health status of society individuals: a narrative review. J Mil Med. 2020;22(2):18492. DOI: 10.30491/JMM.22.2.184 [Persian]

18. Lai J, Ma S, Wang Y, Cai Z, Hu J, Wei N, et al. Factors associated with mental health outcomes among health care workers exposed to coronavirus disease 2019. JAMA Netw Open. 2020;3(3):e203976. PMID: 32202646 DOI: 10.1001/jamanetworkopen.2020.3976

19. Rezaei Dehnavi S. Stigma in mothers with autism spectrum disorder. Except Educ. 2015;7(135):72-83. [Persian]

20. Mahdilouy P, Ziaeirad M. Perceived social stigma and its relationship with demographic and clinical characteristics in adolescents and young people with type 1 diabetes. Iran $J$ Endocrinol Metab. 2019;21(3):153-62. [Persian]

21. Zahraie S, Amini S, Saebi S. The Relationship between Illness Perception, Stigma and Cognitive Fusion with Quality of Life of the women with Multiple sclerosis. Psychol Stud. 2018;14(2):25-41. [Persian]

22. Mohammadi M, Mohtashami J, Arab Khangholi Z. Stigma is more common in patients with mental disorders. Iran J Syst Rev Med Sci. 2020;1(1):61-72. [Persian]

23. Allahtavakoli M. Coping with stress of COVID_19 epidemic. J Jiroft Univ Med Sci. 2020;7(1):253-4. [Persian]

24. Roy D, Tripathy S, Kar SK, Sharma N, Verma SK, Kaushal V. Study of knowledge, attitude, anxiety \& perceived mental healthcare need in Indian population during COVID-19 pandemic. Asian J Psychiatr. 2020;51:102083. PMID: 32283510 DOI: $10.1016 /$ j.ajp.2020.102083 
25. Li A, Jiao D, Liu X, Zhu T. A comparison of the psycholinguistic styles of schizophrenia-related stigma and depression-related stigma on social media: content analysis. J Med Internet Res. 2020;22(4):e16470. PMID: 32314969 DOI: $10.2196 / 16470$

26. Eissa AM, Elhabiby MM, El Serafi D, Elrassas HH, Shorub EM, El-Madani AA. Investigating stigma attitudes towards people with mental illness among residents and house officers: an Egyptian study. Middle East Curr Psychiatry. 2020;27:1-8. DOI: 10.1186/s43045-020-0019-2

27. Murali V, George S. Lost online: an overview of internet addiction. Adv Psychiatric Treat. 2007;13(1):24-30. DOI: 10.1192/apt.bp.106.002907

28. Sally LP. Prediction of internet addiction for undergraduates in Hong Kong. Hong Kong: Baptist University; 2006.

29. Widyanto L, McMurran M. The psychometric properties of the internet addiction test. Cyberpsychol Behav. 2004; 7(4):443-50. DOI: 10.1089/cpb.2004.7.443

30. Chang MK, Law SP. Factor structure for young's internet addiction test: a confirmatory study. Comp Hum Behav. 2008;24(6):2597-619. DOI: 10.1016/j.chb.2008.03.001

31. Masih J, Rajkumar R. Internet addiction disorder and mental health in adolescents. J Depression Anxiety. 2019;S13:2. DOI: 10.4172/2167-1044.S13-002

32. Sehati Yazdi A, Talebian Sharif J. The relationship between Internet addiction and mental disorders (anxiety, stress and depression) and psychological well-being. Quart J Modern Ideas Psychol. 2018;2(6):1-9. [Persian]

33. Warrender D. How use of social media and social comparison affect mental health. Nurs Times. 2020;116(3):58-61.

34. Barany M, Obverts U. Problematic proms in college internet and mobile phone use and clinical students: the role of emotional intelligence. Comp Hum Behav. 2018; 14(2):1182-7.

35. Joseph-Shehu EM, Ncama BP, Mooi N, MashambaThompson TP. The use of information and communication technologies to promote healthy lifestyle behaviour: a systematic scoping review. BMJ Open. 2019;9(10):e029872. PMID: 31662364 DOI: 10.1136/bmjopen-2019-029872

36. World Health Organization. Community-based health care, including outreach and campaigns, in the context of the COVID-19 pandemic. Geneva: World Health Organization; 2020 . 